\title{
Recovery of Rare Earth Elements from Bioleachates by Precipitation
}

Abigail Young Hasler, David W Reed

August 2020

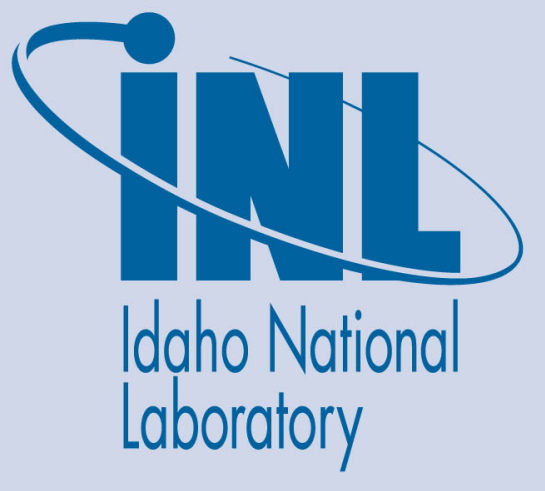

The INL is a U.S. Department of Energy National Laboratory operated by Battelle Energy Alliance 


\title{
Recovery of Rare Earth Elements from Bioleachates by Precipitation
}

\author{
Abigail Young Hasler, David W Reed
}

August 2020

Idaho National Laboratory Idaho Falls, Idaho 83415

http://www.inl.gov

Prepared for the U.S. Department of Energy

Office of Energy Efficiency and Renewable Energy

Under DOE Idaho Operations Office

Contract DE-AC07-05ID14517 


\title{
Recovery of Rare Earth Elements from Bio-leachates by \\ Precipitation
}

\author{
Abigail Hasler \\ Oregon State University, Corvallis, OR \\ Idaho National Laboratory, Idaho Falls, ID
}

Prepared under the direction of David Reed, Ph.D., and Yoshiko Fujita, Ph.D. in the Biological and Chemical Science \& Engineering Department at Idaho National Laboratory. 


\section{TABLE OF CONTENTS}

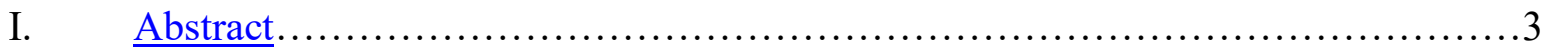

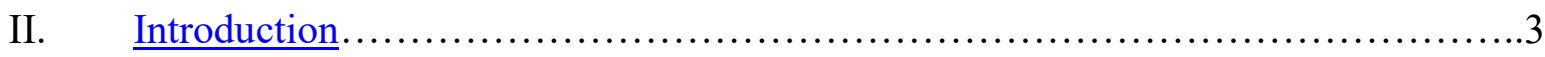

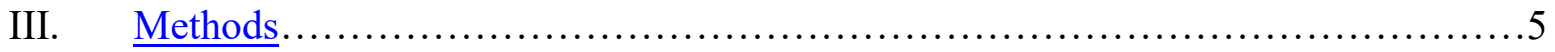

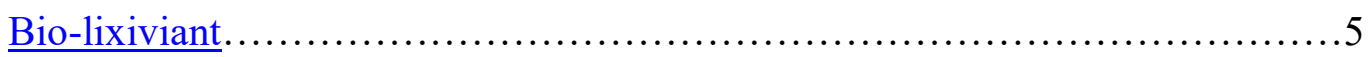

Bioleaching......................................................6

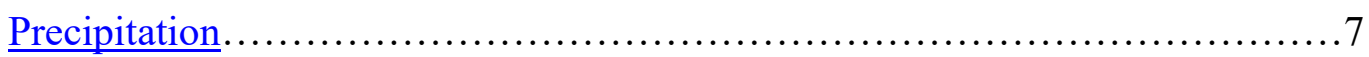

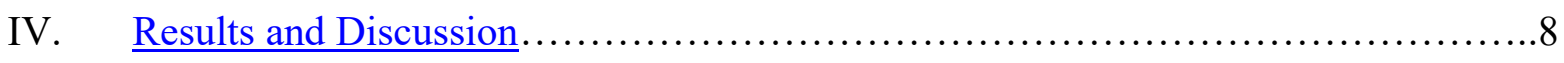

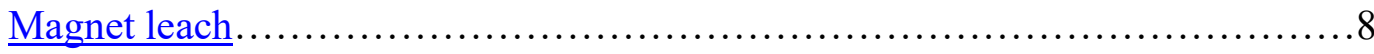

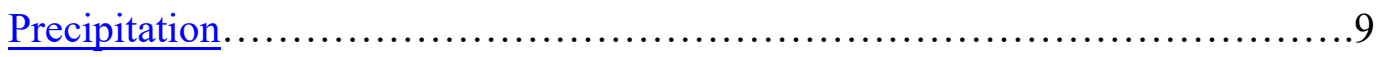

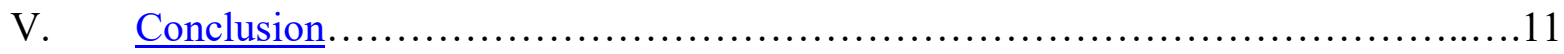

VI. Acknowledgments...................................................... 13

VII. Appendices.............................................................

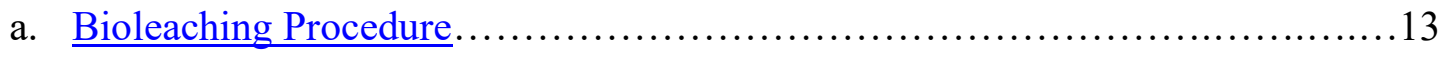

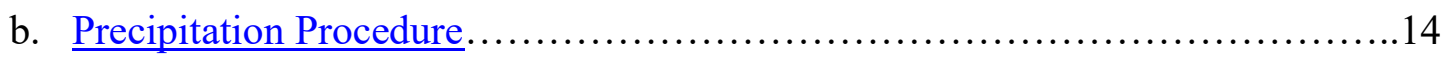

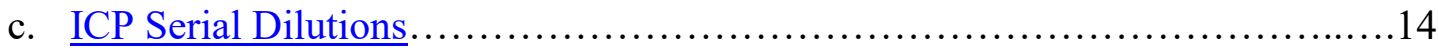

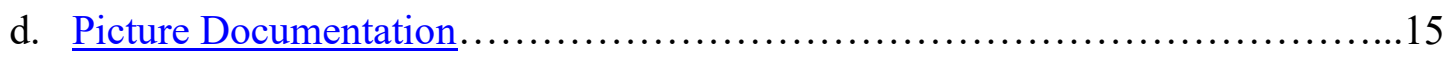

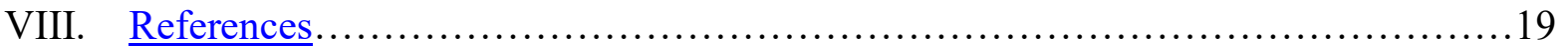




\section{ABSTRACT}

Rare earth elements (REE) are essential components in electronic devices and clean energy technologies, but primary REE production in the US is limited. Consequently, interest in REE recycling from end-of-life materials is increasing. Common practices for REE recycling use concentrated acids or extreme heat, which can be detrimental to the environment. Alternatively, bioleaching uses microorganisms that produce organic acids as an environmentally friendly and economically viable process to recover REE. The bacterium Gluconobacter oxydans was used to produce a bio-lixiviant to dissolve REE. However, once REE are leached with bio-lixiviant, the dissolved REE need additional processing for concentration and refinement. One way to recover and separate the REE from other metals in the solution is to precipitate them prior to down-stream processing. In this study, bio-lixiviant produced by G. oxydans was used to leach REE from mobile device speaker magnets. Sodium sulfate and oxalic acid were then tested at varying stoichiometric excess concentrations with the bio-leachate to precipitate REE. The sodium sulfate reactions resulted in less total precipitate than the oxalic acid precipitations, and the oxalic acid at $8 \mathrm{X}$ and $12 \mathrm{X}$ excess concentrations precipitated all detectable REE.

\section{INTRODUCTION}

Rare earth elements (REE) are used in a variety of electronics; they are contained in magnets, hard drives, hybrid vehicle engines, lasers, and metal alloys found in smart devices. ${ }^{[1]}$ Because the vast majority of REE are not mined in the US, it is imperative to find ways to create a sustainable source of these elements to meet the demand. Currently hydrometallurgical 
technologies are being used to recover these elements from end-of-life materials such as e-waste; however they often use chemicals such as sulfuric acid that are harsh for the environment. ${ }^{[2]}$ Pyrometallurgy can also be used to harvest REE from spent devices, but it uses extremely high heat to do so, and releases large amounts of greenhouse gases. ${ }^{[3,4]}$

Bioleaching, a form of hydrometallurgy, has arisen as a viable way to recycle REE that is potentially as profitable as traditional hydrometallurgy, with similar efficiencies but at a much lower environmental impact. Biohydrometallurgy uses microorganisms to extract and recover metals from wastes or primary feedstocks like ores. In heterotrophic bioleaching organic acids are synthesized by microorganisms and are used to leach metals. ${ }^{[5,6]}$

The purpose of this study was to determine whether REE could be recovered from a bioleachate using methods previously applied for recovering REE from conventional hydrometallurgical leachates. Mobile device magnets containing REE were leached using a biotically produced organic acid lixiviant and methods for downstream precipitation of REE were tested. The gram negative bacterium Gluconobacter oxydans was used to produce the low pH bio-lixiviant; it oxidizes glucose to primarily produce gluconic acid. ${ }^{[7]}$ Oxalic acid and sodium sulfate were tested for recovering REE from the bio-leachate. Hydrometallurgical practitioners commonly use these reagents to precipitate REE from leachate solutions. ${ }^{[8,9,10]}$

Oxalic acid reacts with REE to precipitate rare earth oxalates, which can be subsequently converted to oxides. However, in solutions containing iron, precipitation of ferrous compounds can occur, as reported by Lui et al. (2019). ${ }^{[8]}$ With sodium sulfate as a precipitant, iron will not precipitate until a $\mathrm{pH}$ around 5. However, when using oxalic acid, the strong iron complex created with the oxalate increases the likelihood of iron precipitating out, contaminating the REE 
precipitate. Lui et al. (2019) also reported that when sodium sulfate was at a stoichiometric excess of $8 \mathrm{X},>99 \%$ of REE were recovered from the inorganic acid leachate solution. ${ }^{[8]}$ Excess solutions of oxalic acid or sodium sulfate in hydrochloric and sulfuric acid leachate from magnets yield $\mathrm{REE}_{2}\left(\mathrm{C}_{2} \mathrm{O}_{4}\right)_{3} \cdot 2 \mathrm{H}_{2} \mathrm{O}$ or $2 \mathrm{NaREE}\left(\mathrm{SO}_{4}\right)_{2} \cdot 2 \mathrm{H}_{2} \mathrm{O}$ respectively, as shown in the equations below. $\cdot[\sqrt{[]}$

Sodium Sulfate and Oxalic Acid Precipitations with Inorganic Leachates

$$
\begin{aligned}
& \mathrm{REE}_{2}\left(\mathrm{SO}_{4}\right)_{3}+\mathrm{Na}_{2} \mathrm{SO}_{4}+2 n \mathrm{H}_{2} \mathrm{O} \rightarrow 2 \mathrm{NaREE}\left(\mathrm{SO}_{4}\right)_{2} \cdot n \mathrm{H}_{2} \mathrm{O} \downarrow \\
& 2 \mathrm{REECl}_{3}+3 \mathrm{H}_{2} \mathrm{C}_{2} \mathrm{O}_{4}+n \mathrm{H}_{2} \mathrm{O} \rightarrow \mathrm{REE}_{2}\left(\mathrm{C}_{2} \mathrm{O}_{4}\right)_{3} \cdot n \mathrm{H}_{2} \mathrm{O} \downarrow+6 \mathrm{HCl}
\end{aligned}
$$

\section{METHODS}

Additional details of methods used are provided in the Appendices. Brief descriptions are provided below.

\section{$\underline{\text { Bio-lixiviant }}$}

The SixFors fermentation reactor system was used to produce the bio-lixiviant by growing $G$. oxydans in modified Pikoyskaya phosphate medium with $40 \mathrm{~g} / \mathrm{L}$ glucose, as detailed by Reed et al. (2016). ${ }^{[11]}$ Six batch reactors were monitored by the SixFors system and temperature, air flow, and stirring speed were controlled (Figure 1). The separate bioreactors were autoclaved prior to the run. The $\mathrm{pH}$ probes were calibrated, and the dissolved oxygen probes were polarized overnight and calibrated in the morning by using nitrogen gas and oxygen gas to secure high and 
low references. The $\mathrm{pH}$ and dissolved oxygen were monitored, and the optical density was measured at five time points during bio-lixiviant production. For a period of 40 hours, the temperature was held at $30^{\circ} \mathrm{C}$, stirring speed at $600 \mathrm{rpm}$, and the air flow at approximately 1.06 liters per minute. After 40 hours in the bioreactors, the bio-lixiviant was centrifuged at $6000 \mathrm{~g}$ for half an hour and filtered $\left(0.2 \mu \mathrm{m}\right.$ PES). The bio-lixiviant was then stored at $4^{\circ} \mathrm{C}$ until use (Figure 2).

\section{Bioleaching}

Using sterile techniques to maintain sterility in the lixiviant bottle, $100 \mathrm{ml}$ of bio-lixiviant was added to three one-liter Erlenmeyer flasks. The gluconic acid concentration of the biolixiviant was $253 \mathrm{mM}$ and it had a pH of 2.17. Mobile device speaker sets, comprised of eight parts - an outer casing, inner frame, back plate, four side spacers (two long, two short), and the magnet - were separated from a collection of demagnetized speaker pieces. The speaker pieces were demagnetized by heating in a muffle furnace at $400^{\circ} \mathrm{C}$ and organized into 3 sets (Figure 3,4). The total weight of the magnet speaker set was measured with all eight pieces. The biolixiviant was also weighed to determine the exact lixiviant: solid mass ratio, or pulp density. In this experiment, the speaker set totaled $1.5 \mathrm{~g}$, so the pulp density was approximately $1.5 \%$ (Table 1). The leaching was conducted for 72 hours at $20^{\circ} \mathrm{C}$ with shaking at $150 \mathrm{rpm}$. The bio-leachates were filtered $(0.2 \mu \mathrm{m}$ PES). The filter cake and undissolved magnet pieces were weighed (Table 1) and discarded, and samples were taken for $\mathrm{pH}$ measurement and elemental analysis by inductively coupled plasma with mass spectrometric detection (ICP-MS). 


\section{$\underline{\text { Precipitation }}$}

Sodium sulfate and oxalic acid were used to precipitate REE from the bio-leachate solution. Concentrations that were 12, 8, and 4 times (e.g., 12X, 8X, 4X) the excess stoichiometric amounts were added to the bio-leachate according to the reaction expressions shown in the Introduction; the expected REE concentrations were based on previous experience leaching REE from the magnets.

Stocks of 2.4 M and 1.8 M were made of the sodium sulfate and oxalic acid respectively. The precipitation solutions were made using nanopure water and heated to $50^{\circ} \mathrm{C}$ to effectively dissolve the solid chemicals. When making the stock solutions for sodium sulfate and oxalic acid, larger quantities of each would have been easier to handle, but only $10 \mathrm{ml}$ was made of each to prevent wasting materials. It was difficult to get the oxalic acid dihydrate and sodium sulfate to dissolve at these concentrations, however, after the solutions were heated to $50^{\circ} \mathrm{C}$, and stirred on a hot plate they were able to go into solution.

Immediately after the solutions had been made, they were added to the bio-leachate. For each trial, $2 \mathrm{ml}$ stock solutions, or their dilutions were added to $20 \mathrm{ml}$ of bio-leachate so that each had the appropriate stoichiometric excess. The stock concentrations when added to $20 \mathrm{ml}$ of bioleachate were at $12 \mathrm{X}$ stoichiometric excess to REE concentrations. For the $8 \mathrm{X}$ and $4 \mathrm{X}$ stoichiometric tests, dilutions of the stocks were made and added to the bio-leachates. The reaction vessels were placed in the shaking incubator at $70^{\circ} \mathrm{C}$ for 1 hour and $200 \mathrm{rpm}$ as outlined in Lui et al. 2019. [8]

The precipitate was filtered from solution using $0.7 \mu \mathrm{m}$ Whatman glass microfiber filters (can withstand heat in drying oven). Samples of the filtrate were collected for $\mathrm{pH}$ and ICP-MS. The 
filters were dried overnight for 14 hours at $100^{\circ} \mathrm{C}$ and weighed to determine the mass of solids recovered (Table 2). The ICP-MS measurements of the REE concentrations in the solutions from before and after the precipitations were used to calculate a mass balance and determine how much of the REE was recovered by precipitation.

\section{RESULTS AND DISCUSSION}

\section{$\underline{\text { Magnet leach }}$}

After 72 hours of leaching the liquid in each of the flasks was murky because the magnet and four side spacers had partially dissolved. Flask 1 had a yellow-brown color, flask 2 was slightly darker than 1 and had a green tint, and flask 3 was the darkest and appeared green and red (Figure 5). All of the flasks had 3 speaker pieces still intact: the outer casing, inner frame, and back plate (Figure 6). The filtrates for 1 and 2 were similar colors, yellow and orange, but the filtrate for flask 3 was a much darker orange and red color (Figure 7). The filter cakes followed the same trend with one being lighter and three being the darkest color. The remaining speaker pieces weighed between 0.8-0.83 grams meaning that less than half of the speaker sets were dissolved during the leaching. The initial $\mathrm{pH}$ of the bio-lixiviant was 2.17. Post leaching $\mathrm{pH}$ readings for 1 and 2 were similar: 3.72 , and 3.74 respectively, while 3 was significantly lower at 3.55. This difference might be attributable to a different composition of the pieces in speaker set 3 compared to the other speaker sets, as the undissolved pieces from speaker set 3 were different colors than those from speaker set 1 and 2 . 
Table 1: Initial and final $\mathrm{pH}$ values of magnet bio-leachates and masses of remaining speaker pieces

\begin{tabular}{|r|l|l|l|l|}
\hline \multicolumn{1}{|l|}{$\begin{array}{l}\text { Speaker } \\
\text { set }\end{array}$} & $\begin{array}{l}\text { Initial bio- } \\
\text { lixiviant }(\mathrm{pH})\end{array}$ & $\begin{array}{l}\text { Final bio- } \\
\text { leachate }(\mathrm{pH})\end{array}$ & $\begin{array}{l}\text { Magnet speaker set } \\
\text { weights }(\mathrm{g})\end{array}$ & \multicolumn{2}{l|}{$\begin{array}{l}\text { Mass of remaining } \\
\text { speaker parts }(\mathrm{g})\end{array}$} \\
\hline 1 & 2.2 & 3.7 & 1.55 & 0.81 \\
\hline 2 & 2.2 & 3.7 & 1.56 & 0.82 \\
\hline 3 & 2.2 & 3.6 & 1.54 & 0.80 \\
\hline
\end{tabular}

\section{$\underline{\text { Precipitation }}$}

Immediately upon the addition of all oxalic acid concentrations there was an obvious reaction between the bio-leachate and the oxalic acid; the solution turned yellow and foamed. A yellow precipitate fell out of solution immediately and settled to the bottom of the conical tube. There was no visible reaction with the sodium sulfate solutions. After precipitate was filtered out, the $\mathrm{pH}$ of the filtrates was measured. There was a large decrease from the initial $\mathrm{pH}$ of the combined bio-leachates at 3.5 for the oxalic acid reactions and a minimal change for the sodium sulfate precipitation reactions. The $\mathrm{pH}$ readings of the sodium sulfate concentrations were all around 3.5, not changing significantly from the initial $\mathrm{pH}$ of the bio-leachate. The oxalic acid reactions had very low $\mathrm{pH}$ values, ranging from 2.8 for the $4 \mathrm{X}$ sample to 1.2 for the $12 \mathrm{X}$ sample. 
Table 2: Final $\mathrm{pH}$ values of precipitation reactions and mass of precipitates at different concentrations

\begin{tabular}{|l|l|r|r|}
\hline $\begin{array}{l}\text { Excess } \\
\text { Concentrations }\end{array}$ & $\begin{array}{l}\text { Initial pH (prior to } \\
\text { stock addition) }\end{array}$ & Final pH & Precipitate mass (g) \\
\hline $\mathrm{Na}_{2} \mathrm{SO}_{4} 12 X^{*}$ & 3.5 & 3.6 & 0.05 \\
\hline $\mathrm{Na}_{2} \mathrm{SO}_{4} 8 \mathrm{X}$ & 3.5 & 3.5 & 0.04 \\
\hline $\mathrm{Na}_{2} \mathrm{SO}_{4} 4 \mathrm{X}$ & 3.5 & 3.5 & 0.03 \\
\hline $\mathrm{C}_{2} \mathrm{H}_{2} \mathrm{O}_{4} 12 \mathrm{X}$ & 3.5 & 1.2 & 0.26 \\
\hline $\mathrm{C}_{2} \mathrm{H}_{2} \mathrm{O}_{4} 8 \mathrm{X}$ & 3.5 & 2.1 & 0.12 \\
\hline $\mathrm{C}_{2} \mathrm{H}_{2} \mathrm{O}_{4} 4 \mathrm{X}$ & 3.5 & 2.8 & 0.04 \\
\hline
\end{tabular}

*See the equations: Sodium Sulfate and Oxalic Acid Precipitations with Inorganic Leachates.

The excesses were determined based off the 1:2 REE to sodium sulfate and 1:1.5 REE to oxalic acid ratios. For example, 12X would change sodium sulfate's ratio to 1:24.

The filter cake resulting from each sodium sulfate reaction was grey, all three of the reaction stoichiometries tested resulted in the same color after drying. The precipitate for the oxalic acid immediately after filtering was green for the $4 \mathrm{X}$, muted yellow for $8 \mathrm{X}$, and a bright yellow for the $12 \mathrm{X}$. After drying the precipitate turned a darker yellow for all three concentrations. There was also an outer ring of dark grey that encircled the yellow filter cake. The yellow filter cake is likely iron (II) oxalate because in the precipitation reaction the iron would have created a complex with oxalate and fallen out of solution. At the higher $\mathrm{pH}$ values using a bio-leachate the iron would not have stayed dissolved. After drying, the yellow filter cake was not firmly attached to the filters and could easily be scraped off the filter and separated from the grey material. 
The data collected from the ICP-MS indicated that the $12 \mathrm{X}$ and $8 \mathrm{X}$ oxalic acid precipitation reactions recovered the most REE compared to the $4 \mathrm{X}$ reaction and the sodium sulfate reactions. While the sodium sulfate was able to precipitate out praseodymium, neodymium, gadolinium, and dysprosium, the higher excesses of oxalic acid were able to precipitate out the majority of the detected REE (Table 3).

Table 3: Percentages of recovered $R E E^{* *}$ from precipitation reactions

\begin{tabular}{|l|r|r|r|r|}
\hline Excess Concentrations & Pr (\%) & Nd (\%) & Gd (\%) & Dy (\%) \\
\hline $\mathrm{Na}_{2} \mathrm{SO}_{4} 12 \mathrm{X}$ & 8 & 11 & 30 & 24 \\
\hline $\mathrm{Na}_{2} \mathrm{SO}_{4} 8 \mathrm{X}$ & 12 & 12 & 20 & 19 \\
\hline $\mathrm{Na}_{2} \mathrm{SO}_{4} 4 \mathrm{X}$ & 5 & 8 & 28 & 14 \\
\hline $\mathrm{C}_{2} \mathrm{H}_{2} \mathrm{O}_{4} 12 \mathrm{X}$ & $100 * * *$ & 100 & 100 & 100 \\
\hline $\mathrm{C}_{2} \mathrm{H}_{2} \mathrm{O}_{4} 8 \mathrm{X}$ & 100 & 100 & 100 & 100 \\
\hline $\mathrm{C}_{2} \mathrm{H}_{2} \mathrm{O}_{4} 4 \mathrm{X}$ & 90 & 92 & 25 & 93 \\
\hline
\end{tabular}

** At the time of this report preparation, final ICP-MS data for $\mathrm{Tb}$ and $\mathrm{Fe}$ were not available.

***100 indicates that less than $0.01 \mathrm{ppb}$ was detected in the ICP-MS.

\section{CONCLUSION}

The mass of the filter cakes from the sodium sulfate precipitations were quantitatively much less than the mass of filter cakes resulting from oxalic acid reactions. Because they were generated from the same bio-leachate, the amount of dissolved iron should be the same in all 
reactions, suggesting that the iron in the sodium sulfate precipitations did not fall out of solution, or if it did, it did so to a minimal degree compared to the case with oxalic acid precipitation.

Based on the observations of the precipitation experiment, additional concentrations of oxalic acid should be tested. The mass of the filter cake was larger with increasing concentrations of oxalic acid. Lower concentrations of oxalic acid may produce a higher concentration REE precipitate because there would be less oxalate ions to complex with suspended iron and fall out of solution, but this could also lower REE recovery. According to the ICP data, the measurable amounts of REE recovered were the same between the $12 \mathrm{X}$ and $8 \mathrm{X}$ reactions, indicating that lower concentrations, perhaps between $8 \mathrm{X}$ and $4 \mathrm{X}$ could precipitate a comparable amount of REE, using less precipitant (Table 3).

Another modification would be to decrease the $\mathrm{pH}$ of the bio-leachate, because the lower the $\mathrm{pH}$ the less likely metals would be to precipitate out, therefore ensuring more iron would stay in solution, however this may interfere or limit REE precipitation. Future areas of research, in addition to altering $\mathrm{pH}$ and changing concentrations of precipitating reagents, include increasing REE yield by performing multiple precipitations on a single bio-leachate, perhaps using a combination of chemicals to do so, i.e. both sodium sulfate and oxalic acid. 


\section{ACKNOWLEDGEMENTS}

I'd like to acknowledge my mentors David W. Reed and Yoshiko Fujita from INL for their guidance and support throughout my internship. Thanks are also due to Caitlin A. McNamara for her continued training and direction, Mary E. Case for her instruction in the use of the TXRF, Kastli D. Schaller for analyzing my bio-lixiviant samples for organic acid content, and Luis A. Diaz Aldana for his advice regarding precipitation. I'd like to thank the Department of Energy and the SULI program and INL for allowing me to work here this summer. This work has also been supported by the Critical Materials Institute, an Energy Innovation Hub funded by the U.S. Department of Energy, Office of Energy Efficiency and Renewable Energy, Advanced Manufacturing Office. Critical Materials Institute funding was provided at INL through DOE Idaho Operations Office Contract DE-AC07-05ID14517.

\section{APPENDICES}

\section{APPENDIX A: Bioleaching Procedure}

1. Separate mobile device speaker parts from the demagnetized pile, find three sets of speaker parts and magnet.

2. Weigh the magnet separately and with the other speaker components. The weight should be around $1.5 \mathrm{~g}$, so that the pulp density for leaching will be $1.5 \%$ if $100 \mathrm{ml}$ of biolixiviant is used.

3. Using sterile techniques (Bunsen burner) add $100 \mathrm{ml}$ of lixiviant each to magnet set, oneliter flasks with screw on lids. Weigh the lixiviant.

4. Speaker components do not need to be sterilized. Add speaker parts into the lixiviant in flasks.

5. Leach for three days at 20C, 150 RPM.

Harvest:

1. The leachate does not need to be centrifuged. Filter using vacuum and $250 \mathrm{ml}$ filters (0.2 $\mu$ PES), into separate bottles. 
2. Collect $5 \mathrm{ml}$ in a $15 \mathrm{ml}$ conical for ICP, $1 \mathrm{ml}$ in $1.5 \mathrm{ml}$ microcentrifuge tube for TXRF, and $1 \mathrm{ml}$ for $\mathrm{pH}$ in glass tube.

3. Measure $\mathrm{pH}$ and TXRF, send ICP out for testing.

\section{APPENDIX B: Precipitation Procedure}

1. Add two bio-leachates together to have enough for six trials. Record combined $\mathrm{pH}$.

2. Add $20 \mathrm{mls}$ of the combined bio leachate into $650 \mathrm{ml}$ conicals, labeled with chemicals being used for precipitation.

3. Begin heating shaking incubator (70C).

4. Prep stock solutions.

a. Using nanopure water create $2.4 \mathrm{M}$ and $1.8 \mathrm{M}$ stock solutions of sodium sulfate and oxalic acid, respectively.

b. At $50{ }^{\circ} \mathrm{C}$ on a hot plate, mix the solutions for 5 minutes, or until completely dissolved.

c. See Precipitation Concentration spreadsheet for calculations and stock solution measurements.

5. The determined stoichiometric excesses for these precipitations were 12,8 , and 4 for each sodium sulfate and oxalic acid. Depending on the amount of excess, add stock solution and autoclaved nanopure water (for a total of $2 \mathrm{ml}$ added volume) to the conical tubes.

6. Shake in incubator at $70 \mathrm{C}$ for one hour.

7. Weigh filters. Label sample conical tubes for excess filtrate, $\mathrm{pH}, \mathrm{ICP}$, and TXRF analysis.

8. Filter using Whatman glass microfiber filters with $0.7 \mu \mathrm{m}$ pore size.

9. Section out filtrate for ICP $(5 \mathrm{ml})$, TXRF $(1 \mathrm{ml}), \mathrm{pH}(2 \mathrm{ml})$, and the remainder of the filtrate $(12-15 \mathrm{ml})$ in another conical.

10. Place the filters in a metal tray for oven. Put the filters in a glass pan, and into the drying oven at 100C 12 hours/ overnight.

11. Measure $\mathrm{pH}$ of filtrate.

\section{APPENDIX C: ICP Serial Dilutions}

1. Add $50 \mu \mathrm{l}$ of concentrated nitric acid to the $5 \mathrm{ml}$ of sample used for ICP analysis.

2. Take $0.1 \mathrm{ml}$ of the previous solution and add to $50 \mathrm{ml}$ of $0.2 \mathrm{M}$ nitric acid, vortex this solution.

3. Add $0.1 \mathrm{ml}$ of the previous solution to $50 \mathrm{ml}$ of $0.2 \mathrm{M}$ nitric acid and vortex.

4. Add $0.5 \mathrm{ml}$ of the previous solution to $15 \mathrm{ml}$ of $0.2 \mathrm{M}$ nitric acid and vortex. This results in a final dilution of 1:7,500,000 which is used for ICP analysis. 
APPENDIX D: $\underline{\text { Picture Documentation }}$

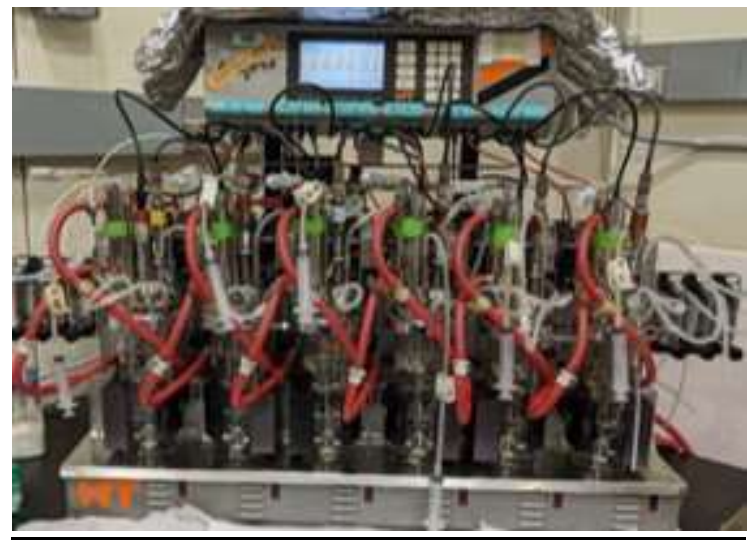

Figure 1: Hasler, A., 2020. SixFors Reactor

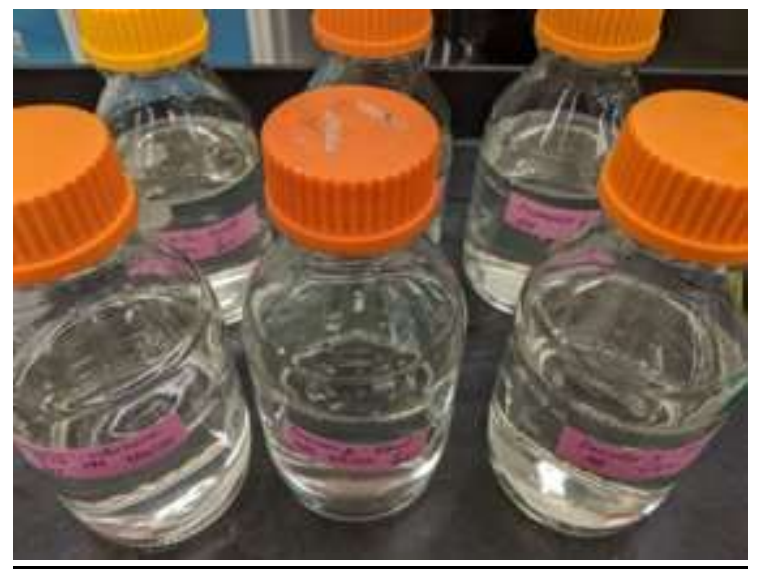

Figure 2: Hasler, A., 2020. Bio-lixiviants

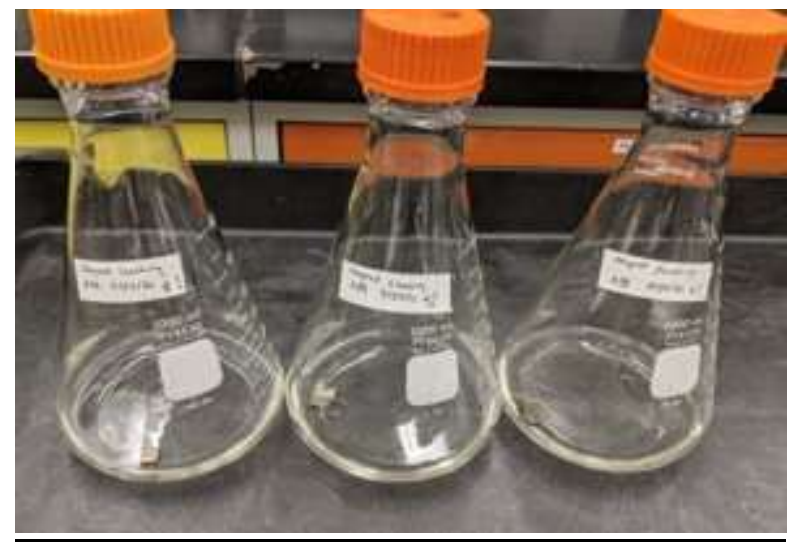


Figure 3: Hasler, A., 2020. Bio-lixiviant and Magnets Prior to Leaching

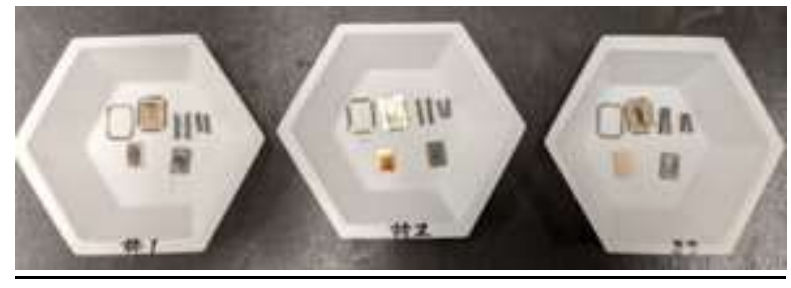

Figure 4: Hasler, A., 2020. Speaker Magnet Sets

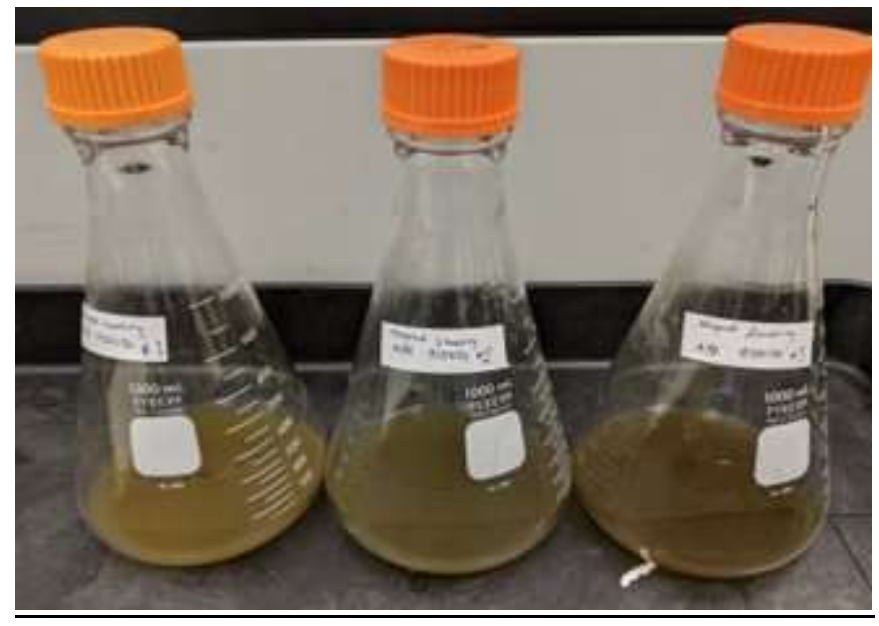

Figure 5: Hasler, A., 2020 Magnet Bio-leachate

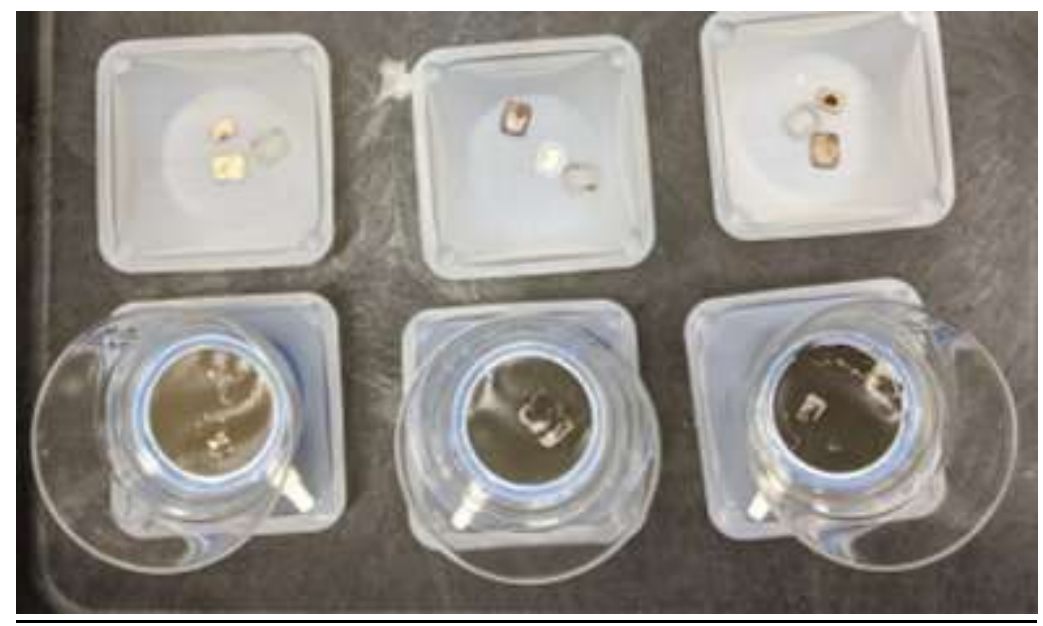

Figure 6: Hasler, A., 2020. Magnet Filter Cake and Remaining Speaker Pieces 


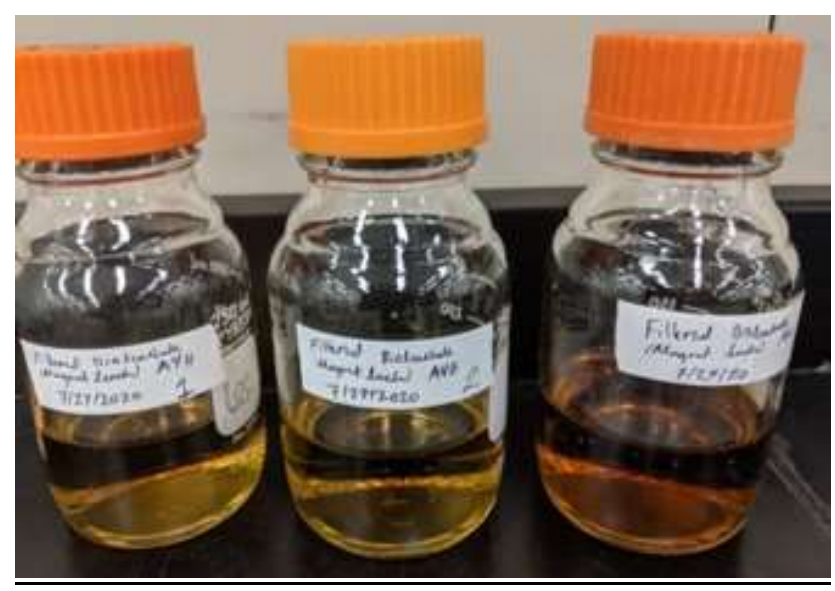

Figure 7: Hasler, A., 2020. Filtered Bio-leachate

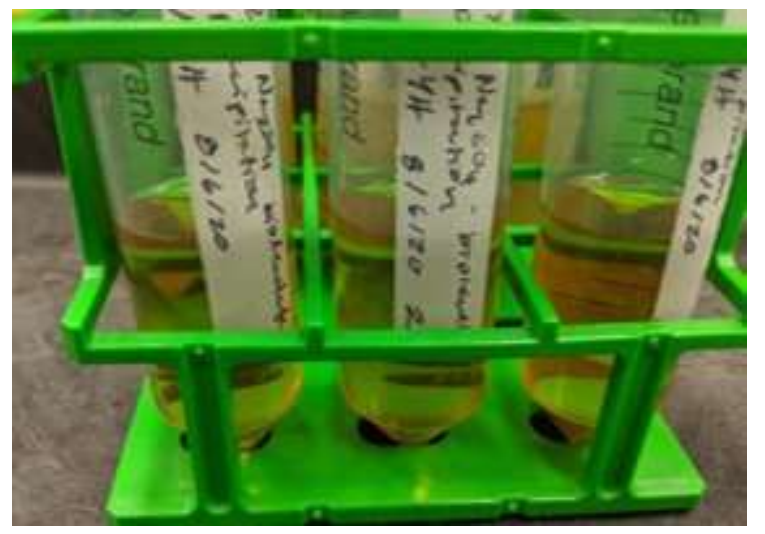

Figure 8: Hasler, A., 2020. Sodium Sulfate Precipitation Reaction
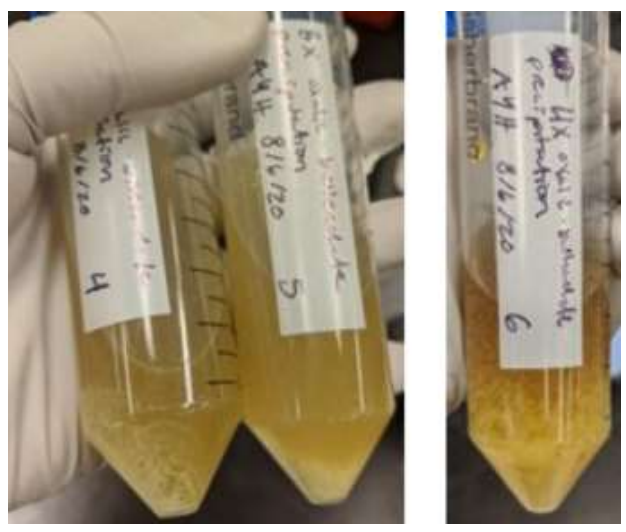

Figure 9: Hasler, A., 2020. Oxalic Acid Precipitation Reactions 


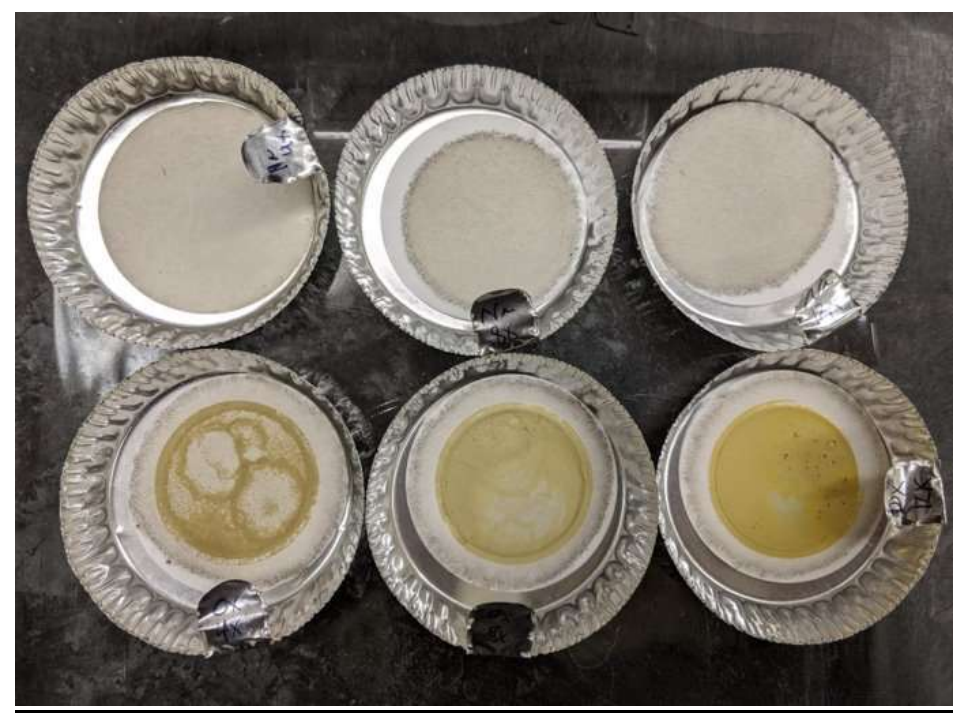

Figure 10: Hasler, A., 2020 Precipitant Filter Post-Drying

Top Row Sodium Sulfate L to R: 4x, 8x, 12x

Bottom Row Oxalic Acid L to R: 4x, 8x, 12x 


\section{REFERENCES}

1. Humphries, M. (2010, September 30). Rare Earth Elements: The Global Supply Chain.

2. Michelis, I., Ferella, F., Varelli, E., \& Vegliò, F. (2011, August 12). Treatment of $\underline{\text { exhaust fluorescent lamps to recover yttrium: Experimental and process analyses. }}$

3. SB. Castor, J., Mark William. Kennedy, T., S. Peelman, Z., T. Sun, M., JR. Pandya, B., \& S. Arnout, E. (1970, January 01). Pyrometallurgical Treatment of Apatite Concentrate with the Objective of Rare Earth Element Extraction: Part I.

4. Kulczycka, J., Lelek, Ł, Lewandowska, A., Wirth, H., \& Bergesen, J. (2015, November 23). Environmental Impacts of Energy-Efficient Pyrometallurgical Copper Smelting Technologies: The Consequences of Technological Changes from 2010 to 2050.

5. Bosecker, K. (1997, July 01). Bioleaching: Metal solubilization by microorganisms.

6. Kaksonen, A., Boxall, N., Gumulya, Y., Khaleque, H., Morris, C., Bohu, T., Lakaniemi, A. (2018, June 25). Recent progress in biohydrometallurgy and $\underline{\text { microbial characterisation. }}$

7. Pronk, J., Levering, P., Olijve, W., \& Dijken, J. (2002, December 10). Role of NADP-dependent and quinoprotein glucose dehydrogenases in gluconic acid production by Gluconobacter oxydans.

8. Liu, F., Porvali, A., Halli, P. et al. Comparison of Different Leaching Media and Their Effect on REEs Recovery from Spent Nd-Fe-B Magnets. 
9. Zhang, P., Yokoyama, T., Itabashi, O., Wakui, Y., Suzuki, T., \& Inoue, K. (1998, December 07$)$. Hydrometallurgical process for recovery of metal values from spent nickel-metal hydride secondary batteries.

10. Önal, M., Borra, C., Guo, M., Blanpain, B., \& Gerven, T. (2017, July 06). Hydrometallurgical recycling of NdFeB magnets: Complete leaching, iron removal and electrolysis.

11. Reed, D., Fujita, Y., Daubaras, D., Jiao, Y., \& Thompson, V. (2016, August 22).

Bioleaching of rare earth elements from waste phosphors and cracking catalysts. Retrieved from https://www.sciencedirect.com/science/article/pii/S0304386X16305473 